\title{
AUTOBIOGRAPHIES OF INDUSTRIAL WORKERS
}

SOURCES OF NORWEGIAN SOCIAL HISTORY

In the study of social history the industrial working class has by no means been neglected. Not in Norway and not in most other countries. But what has aroused interest is mainly one aspect of the whole topic: The part played by the great labour and trade union organizations in the struggle for power in political and industrial life.

The plain, ordinary working men, however, are often lost in the fog of statistics. We may know how many workers were employed at a certain time in the Norwegian paper mills or dockyards. We may even ascertain their average income or their normal working hours. But we don't know much about what life looked like to those people. What did they eat, and how much could they afford to eat? How was the interior of their houses, seen through their own eyes? What did they think and feel about their own conditions in the workshop and at home?

It is, however, still possible to get the answers to such questions by asking those concerned. The industrialization is a fairly recent development in Norway. We had, indeed, some cotton mills equipped with English machinery as early as the middle of the $1840^{\circ} \mathrm{s}$, but this industry did not affect more than two or three of the towns. Only in the I 860's the steam engine was utilized for saw-mills and planing mills. In the last two or three decades of the I th $^{\text {th }}$ century the pulp and paper industry developed. And about 1900 began the very important growth of chemical and metallurgical industries based on hydroelectric power.

To-day Norway is to a fairly great extent an industrial country, with about one third of the working population employed in industry. But this, then, is a very recent development. In i 860 there were merely $\mathbf{I} 7000$ industrial workers, mostly employed in very small workshops. In 1870 the number was doubled. In 1900 it was four times as large as in 1860 , and in 1913 seven times as large; industry then employed about 120.000 workers.

This means that the greater part of the industrialization of Norway is still within reach of the memory of man. There still live thousands of 
old workers who have personally experienced the "Industrial Revolution". Of course no one now remembers the first cotton mills in Norway. But those people had their childhood and youth in a preindustrial rural society. They started work for instance as farm hands, with wages paid in the form of food, lodging and clothes - and nothing or next to nothing in cash. They lived more or less in the same way as their fathers and grandfathers before them. Only as adults did they meet industry: They may have met it in the way that they themselves moved away to some factory. Or, in other cases, industry moved into the countryside, meeting the rural workers there.

This is part of the background of an attempt which is made so to speak to create a new group of sources to the most recent social history. Following the example set by the Nordic Museum (Nordiska Museet) in Sweden, we have at the Norwegian Folk Museum (Norsk Folkemuseum) during some years tried to persuade as many old workers as possible to write down their auto-biographies - or to tell about their lives to other people who can put their narratives in writing or register them by means of a tape recorder.

I must stress the fact that the work of collecting these sources is still in progress. But at least from some few branches of industry we have got together a material which may be regarded as fairly satisfactory - mainly from the paper and pulp industry and the sawmill and planing industry, two of the most important branches of Norwegian industry.

The aim is not to collect a statistical material, and our questionnaires contain no questions to be answered with "yes" or "no" or with one or two other simple words. The questions are there to help our informants to get along with the telling of what they themselves regard as important. But in addition we often have to induce them to describe such matters as they themselves regard as too self-evident or too unimportant to deserve any mention. We ask them to describe their childhood homes, the furniture and the food. We invite them to give their opinions on the foremen and employers they have met. Some of the questions may be rather personal. But one of the great satisfactions of this work is the willing response from the great majority of those whom we approach. They know that the social transformation during their lifetime has been so profound as to deserve description.

Of course the narratives collected vary greatly both in quality and in length. Some consist of a couple of pages, others are indeed books of more than a hundred pages.

The reliability of these life-stories as historical sources is questionable in more ways than one. Each one of the informants will have to be treated with the same sort of caution as any other auto-biographer. 
We must form an opinion about his temperament, which may lead him to understatements or overstatements. We must find out what axes he has to grind. And of course we shall have to control his narrative wherever possible from other sources.

The reliability is naturally very different according to what kind of information you want. Generally you cannot for instance trust statements on wages or dates: It is too easy to forget about such exact details. But a man who lived in the same house, say till he was is years old, will ordinarily be able to describe that house in detail and with great reliability. Still, allowance must be made for temperamental differences, which make one narrator stress the fact that the walls were so open that there sometimes were heaps of snow on the floor in the morning. While another man, living under equally poor conditions, especially remembers the pleasant family life and the cosy evenings - even if they had to sleep three or four people in one bed.

The dwelling and its fittings will, however, be a relatively permanent thing and therefore easy to remember. It is more difficult to evaluate the information on the food. One informant will give the picture of general hunger, because he clearly remembers one or two hungry days. While another, according to his temperament, will generalize from de memory of one or two happy and substantial meals. In these cases, however, the mistakes and the exaggerations will generally be corrected if we have ten or twenty informants, describing more or less the same milieu.

The most important problem, however, is whether these life stories give any trustworthy information on those topics which we $e_{j} \quad y$ wish to clarify: The workers' way of looking at life and at their own social conditions, whether they felt oppressed or more or less content. Did they consider the employer an enemy, or were they on the contrary grateful to the man who "gave them work"? Did they feel that the industrial development on the whole was to the benefit of the workers or perhaps that it meant a growing misery?

I can merely touch upon some of the problems involved. It is, however, important to stress that our informants are not representative of the whole Norwegian working class. We depend to a large extent on the more articulate people, on those who are able to formulate their opinions with some ease, in writing or speech. Those people will often be identical with the local leaders of the workers, they have represented their comrades on the boards of the trade union branches, on the town councils or elsewhere. We must therefore expect them to stress the importance of political and union activity more heavily than the average worker. It is probable too that our informants wi be inclined to underline the antagonism between workers and em 
ployers rather heavily, since this antagonism has been a very important part of the ideology of the labour movement.

In addition comes that everyone will have much difficulty in remembering his own views and feelings and in reporting them truthfully. You may for instance ask a man whether he liked working in a certain factory. The answer may depend on many things which really has nothing to do with the question. Perhaps it is part of his moral upbringing that all kinds of hard work is a blessing and that contentment is an important Christian virtue. Or, on the contrary, it may be part of the ideology acquired in the trade union struggle, that the employer is the enemy and the oppressor, and that work in a capitalist enterprise is always evil. Perhaps also the narrator as a middle-aged man has been engaged in bitter struggles with the employers; he will then easily project that antagonism back to his early youth.

All these reflexions on the source value of the workers' autobiographies will lead to the conclusion that we can never rely much upon what one single narrator tells us, we need many informants from approximately the same milieu. And when it comes to memories of opinions and feelings, we must dismiss most of the direct and unsubstantiated statements, and keep to those narratives which more indirectly express thoughts or feelings through circumstantial stories of what really happened.

I think, however, that I had better give some examples to show what kind of evidence I believe we can trust.

Those people who started work in the oldfashioned agriculture, as cottars or farm hands, are practically unanimous in maintaining that factory work to them meant a very important step forward. I can hardly think of any influence which should induce them to speak or think in this way, if it was not simply the truth. They substantiate their statements with figures of what they earned in agriculture and in industry. But it is more impressive to hear what they have to tell about their way of life. An old woman remembers the late i 890 's when she was newly married to a cottar. She describes how hungry she sometimes was. But she didn't dare to touch the food - because she had barely enough for the children. Then her husband started work in a wood pulp factory, his weekly wage was at once doubled, and they could afford sufficient food for all family members, even for the mother.

One of the striking features in most narratives on living conditions among the agricultural workers is the stress laid on food. To characterize a bad workplace, an old farm hand will tell you how monotonous and how inadequate the food was, how few slices of bread he got, how strictly the butter was rationed, and so on. On the other hand he may characterize another place by saying: "Such awfully good food as I got 
there, you couldn't match. I grew so fat while I was there, that I could hardly move."

This kind of interest in food is of course the outcome of a situation where it was still a daily problem to get enough food for to-morrow, where hunger was never very far away. When sons of factory workers have much less to tell about food - so much less that we can hardly get them to describe one single meal - it must be a sign that the standard of living among the factory workers from the outset was so much higher that food was now a comparatively uninteresting matter-of-course.

Descriptions of the workers' tenements around the old factories often give a strong impression of overcrowding and of insanitary conditions. We may hear of large families, living in one room and dividing a small kitchen with one or two other families. At a match factory, for instance, which needed a large number of young girls for work, the families might even be obliged to take two or three girls as lodgers in their one room - or, at best, accomodate them in the kitchen. Even so, I think it would be risky to conclude that industrialization to these people meant a worsening of housing conditions. An old navvy, who started his railway work in the mountains in Northern Norway, describes the simple wooden barracks for the workers. But his standard of comparison is the condition of the fishermen during the great seasonal fisheries where he himself had participated for some years. So he finds that the conditions for the navvies compares very favourably with the over-crowding in the fishing stations. A saw-mill worker criticizes the bad lodgings for the workers as late as about I9ro; but he concludes that at the time nobody complained, because it was no worse than what they were used to as lumbermen or fishermen.

The economic advantage of factory work was in fact evident to everyone, and the choice of occupation was of course very strongly influenced by this. A man born in 1885 explains carefully what he earned, year by year, as a farm hand. In 1906 he married and the first child was expected: "Then I thought I had to try some other kind of work. I applied for and got work in the paper industry."

It was not, however, merely the higher wages which constituted the attraction of factory work. In the factory people found more "safety" and more "freedom" than they had experienced in agriculture. But "safety" in this connection simply means economic safety. The cottars and the farm hands were often unemployed a great part of the year, and they were liable to be dismissed when the farmers' own sons grew up, or when they themselves got too old to be fully effective workers. Of course the "safety" in the factories was far from absolute. Many mills closed down for some weeks or months in the winter, and an economic 
crisis might lead to an even longer stop. But industry was expanding, and in general the workers were clearly right when they said: "You could reckon you were safe for life when you came to the factory".

The "freedom" in industry is a more complex notion than the "safety". When an old worker says that he got more freedom in the factory than in the farm, he will think of several things. First, the working hours. In the paper and pulp industry the workers ordinarily worked 12 hour shifts, and their meal times were rather irregular. Even so, a man coming from farm work, will say: "In the factory it was good, because we had shifts; so we were free, when the shift was finished". The point simply is that the farm hands had no free time: They lived on the farm and had to be at the disposal of their master at any time, from very early in the morning till very late at night. A man coming from a farm to a paper mill, states: "We did not think working hours long". In the same breath he goes on by describing how he sometimes worked two or even four shifts at a stretch - that is up to 48 hours. But even so, ordinarily he had some hours to himself every day, which certainly was a considerable gain in freedom.

The more immaterial components of "freedom" is of course more difficult to evaluate. A lumberman may describe how he missed the free life in the forest, when he started work at a paper mill. It is not unusual to hear old timber-yard hands saying that they would never work inside a saw-mill or another factory, because they could not stand the stuffy air. To them the open air is part of their freedom.

Factory discipline is also implied in their use of the word freedom. In the same way as the farm hands would characterize the different farms according to the food they got there, factory workers may distinguish between good and bad workplaces according to the kind of discipline prevailing. When they say that one factory was "a free and good working place", they may mean that there was no foreman haranguing the workers all day, that it might be possible to get a nap during the night shift, and, in short, that the workers within reasonable limits might arrange matters according to their own pleasure.

This kind of freedom, of course, was to a great extent dependent on the personality of the employers, up to the time when the trade unions caused a more or less complete change in these conditions. The old workers' life stories contain, however, no indication that factory discipline was felt to be a general limitation of freedom as compared with pre-industrial conditions.

Most of our old informants in the saw-mill and planing industry are born and bred near the mills, as sons of the first generation of workers in the steam-powered saw-mills. They very often started work in the mill about the age of ten or twelve. According to present day con- 
ceptions, industrial child labour certainly is a great evil, and the general belief probably is that the children concerned had a very unhappy childhood. The fact is, however, that hardly any of those who have personal experience complain of the early child labour, and a large number of them directly and indirectly make it clear that they looked forward to the day when they could start work, and that they definitely liked to be at the mill. I think that this attitude among the children is perhaps the most convincing proof that the early factories and mills were not generally regarded with repugnance.

This, of course, does not mean that the factories about the end of the last century were peaceful idyls. Strikes and other kinds of labour conflicts prove the existence of discontent among the workers. But such dissatisfaction as there was, did not come as a direct sequel of industrialization, and it was not provoked by comparisons with preindustrial conditions. Strikes and industrial unrest occurred more frequently the further the workers were removed from the preindustrial, agricultural society. Small factories, recruiting their workers from the surrounding countryside, had as a rule very small labour problems. Unrest was more common in factories which had to draw their labour from far-away districts. When the industrial workers were more or less isolated from the old rural society, they ceased to compare their own conditions with those of the agricultural workers. Then, the standards created by industry itself, made them lay heavier claims than before, and labour conflicts followed.

(This contribution is a paper read to the International Congress of Historical Sciences in Rome, 1955). 